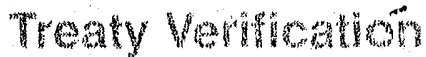

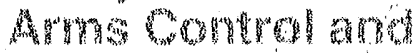

Tha

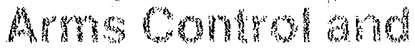

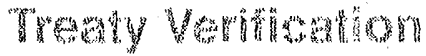

Arrus controt and

Trom

Arms Control and

Treaty Verification

Arms Control and

Treaty Verification

Arms Control and

Treaty Verification

Armas Comtrol whol

Treaty Wertication

Arrvs Control and

Trealy Verithoation

Amos Controb ond

\title{
Intrinsic TLI Surface Tag Directly Authenticated by a SEM (Closeout Report)
}

Treaty Verificalion

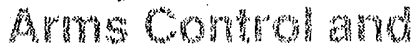
Treaty Verlicantion Arms Combol and

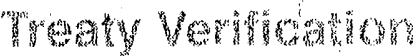
Arms Oontro! a Treaty Verwication Armas rombol and Treaty Vorstigation Ams Control and Treatly Verituation Antres controt and Treaty Veritioation Arms control and Treav Veringation Arms Control and Treary Vericication Arutes Control and Treaty Verifloaton

\author{
by N. J. Zaluzec, A. Philippedes, \\ R. G. Palm, A. De Volpi, \\ and J. W. Holland
}

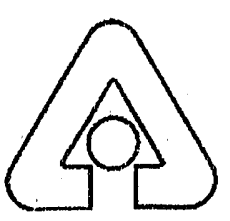

Argonne National Laboratory, Argonne, Illinois 60439

operated by The University of Chicago

for the United States Department of Energy under Contract W-31-109-Eng-38

Notice

The work reported herein is part oi a research and development program for arms control and treaty veríication and does not imply current or future policy positions or technical preferences of any agency of the U.S. Government. 
Argonne National Laboratory, with facilities in the states of Illinois and Idaho, is owned by the United States government, and operated by The University of Chicago under the provisions of a contract with the Department of Energy.

\section{DISCLAIMER}

This report was prepared as an account of work sponsored by an agency of the United States Government. Neither the United States Government nor any agency thereof, nor any of their employees, makes any warranty; express or implied, or assumes any legal liability or responsibility for the accuracy, completeness, or usefulness of any information, apparatus, product, or process disclosed, or represents that its use would not infringe privately owned rights. Reference herein to any specific commercial product, process, or service by trade name, trademark, manufacturer, or otherwise, does not necessarily constitute or imply its endorsement, recommendation, or favoring by the United States Government or any agency thereof. The views and opinions of authors expressed herein do not necessarily state or reflect those of the United States Government or any agency thereof.

Reproduced from the best available copy.

Available to DOE and DOE contractors from the Office of Scientific and Technical Information

P.O. Box 62

Oak Ridge, TN 37831

Prices available from (615) 576-8401, FTS 626-8401

Available to the public from the

National Technical Information Service

U.S. Department of Commerce

5285 Port Royal Road

Springfield, VA 22161 
Distribution Category:

General, Miscellaneous, and Progress Reports

(UC-700)

ANL/ACTV-91/3

ANL/ACTV $--91 / 3$

DE92 009920

\section{ARGONNE NATIONAL LABORATORY \\ 9700 South Cass Avenue \\ Argonne, Illinois 60439}

INTRINSIC TLI SURFACE TAG

DIRECTLY AUTHENTICATED BY A SEM

(Closeout Report)

by

N. J. Zaluzec, A. Philippedes,

R. G. Palm,* A. De Volpi,**

and J. W. Holland*

Materials Science Division

November 1991

Work sponsored by

U. S. Department of Energy

Office of Arms Control

* Reactor Engineering Division 


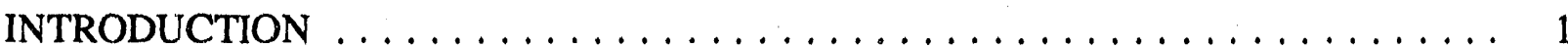

1.0 Proof-of-Concept Portable Scanning Electron Microscope $\ldots \ldots \ldots \ldots \ldots \ldots$

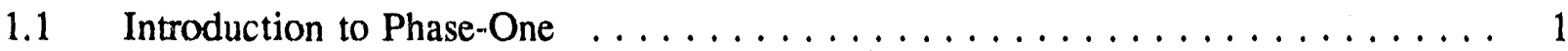

1.2 Technical Results and Discussion $\ldots \ldots \ldots \ldots \ldots \ldots \ldots \ldots \ldots \ldots$

1.2.1 TLI Curvature and Surface Roughness $\ldots \ldots \ldots \ldots \ldots \ldots \ldots$

1.2.2 Proof-of-Concept Portable Scanning Microscope $\ldots \ldots \ldots \ldots \ldots \ldots$

1.3 Conclusions from Phase-One Portable SEM

Development Effort $\ldots \ldots \ldots \ldots \ldots \ldots \ldots \ldots \ldots \ldots \ldots$

2.0 Design of a Portable SEM for Tagging TLIs $\ldots \ldots \ldots \ldots \ldots \ldots \ldots \ldots \ldots$

2.1 Introduction to Phase-Two $\ldots \ldots \ldots \ldots \ldots \ldots \ldots \ldots \ldots$

2.2 Other Portable SEM Designs $\ldots \ldots \ldots \ldots \ldots \ldots \ldots \ldots \ldots \ldots$

2.2.1 NASA's SEMPA Design . . . . . . . . . . . . . . . . 8

2.2 .2 Raith's Design . . . . . . . . . . . . . . . . . 9

2.2.3 Discussions of Other Designs . . . . . . . . . . . . . . . 9

2.3 PSEM Lens Design $\ldots \ldots \ldots \ldots \ldots \ldots \ldots \ldots \ldots \ldots \ldots \ldots$

2.3.1 Optimizing a PSEM for Arms Control Applications . . . . . . . . . . 10

2.3.2 Measurements Made to Define

Magnetic Field Requirements . . . . . . . . . . . . . . . . . . . . . . . 10

2.3 .3 New Lens Design . . . . . . . . . . . . . . . . . . . . . 12

2.3.4 SEM Column Optimized for Tagging $\ldots \ldots \ldots \ldots \ldots \ldots \ldots \ldots$

2.4 Tagging SEM System $\ldots \ldots \ldots \ldots \ldots \ldots \ldots \ldots \ldots \ldots \ldots$

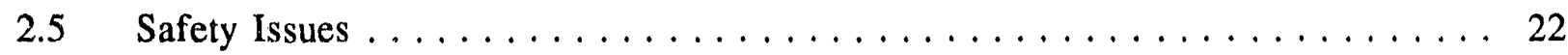

2.6 Conclusions from Phase-Two Design Efforts $\ldots \ldots \ldots \ldots \ldots \ldots \ldots$

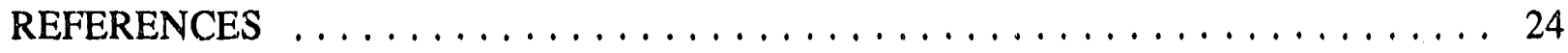

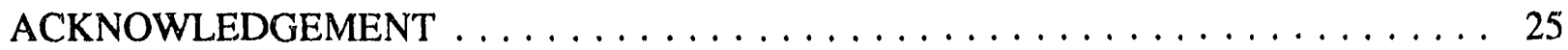

APPENDIX 1. Trip Report to Evaluate Raith SEM $\ldots \ldots \ldots \ldots \ldots \ldots$ 


\section{LIST OF FIGURES}

No.

1.1 Schematic Illustrating Mating a Portable SEM

to a Curved TLI ............................ 3

1.2 Scanning Electron Microscope-TLI Surface,

Close-up Photo $\ldots \ldots \ldots \ldots \ldots \ldots \ldots \ldots \ldots \ldots \ldots \ldots \ldots, 4$

1.3 Scanning Electron Microscope-TLI Surface,

Comprehensive Photo .......................... 5

1.4 Scanning Electron Microscope Photo of TLI Surface

with a Drill Bit Indent $\ldots \ldots \ldots \ldots \ldots \ldots \ldots \ldots \ldots \ldots, 7$

2.1 Measurements of Phase-One Operating Parameters $\ldots \ldots \ldots \ldots \ldots \ldots 11$

2.2 Condenser Lens Design $\ldots \ldots \ldots \ldots \ldots \ldots \ldots \ldots \ldots \ldots \ldots \ldots \ldots$

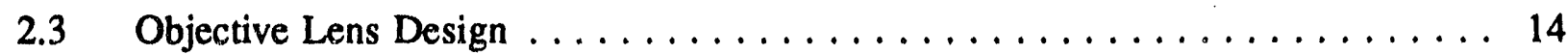

2.4 Coil Magnetic Field Linearity $\ldots \ldots \ldots \ldots \ldots \ldots \ldots \ldots \ldots \ldots \ldots$

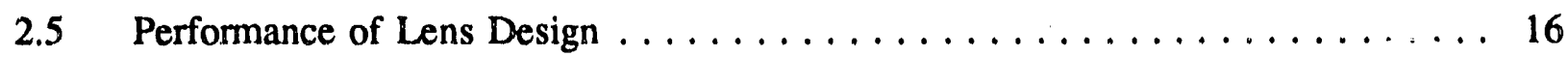

2.6 Schematic of a Tagging SEM Electron Column $\ldots \ldots \ldots \ldots \ldots \ldots \ldots \ldots$

$2.7 \quad$ Photo of Tagging SEM Electron Column Mockup . . . . . . . . . . . . . 19

2.8 Schematic of Tagging Optimized SEM $\ldots \ldots \ldots \ldots \ldots \ldots \ldots \ldots \ldots \ldots$

A-1 Raith Pearl Portable SEM Examining Hood of a Van $\ldots \ldots \ldots \ldots \ldots$

\section{LIST OF TABLES}

№. $\quad$ Page

2.1 Selection and Motivation for Major Components $\ldots \ldots \ldots \ldots \ldots \ldots \ldots 21$

2.2 Comparison of Phase-One and Phase-Two SEMs $\ldots \ldots \ldots \ldots \ldots \ldots \ldots$ 


\title{
INTRINSIC TLI SURFACE TAG DIRECTLY AUTHENTICATED BY A SEM
}

by

\author{
N. J. Zaluzec, A. Philippedes, R. G. Palm, A. DeVolpi and J. W. Holland
}

\begin{abstract}
The objective of this task was to develop a unique identifier (tag) for TreatyLimited Items (TLIs) in arms control applications. This tag is authenticated by the direct attachment of a portable Scanning Electron Microscope (SEM) to the TLI. It is an intrinsic tag with two distinct TLI surface-authentication signatures, consisting of topography and atomic composition. Authentication is accomplished by comparing the field-inspection signature with the baseline signature. Because this tag has two unique signatures, it is considered extremely resistant to counterfeit attempts. Since commercial SEMs are rather large instruments intended to observe small samples introduced into a vacuum chamber integral to the instrument, it was initially necessary to demonstrate that interfacing an SEM to a large TLI was feasible. The first phase demonstrated that an SEM could obtain high-resolution images of a large, curved, simulated TLI surface. A used commercial SEM was modified to accomplish the first phase, and this instrument is referred to as the proof-ofconcept portable SEM. The second phase began with a systematic evaluation of the design alternatives necessary to produce a portable SEM suitable for TLI tag authentication. Since the electron column design of the SEM was the central component that drove the selection of the rest of the system, this phase continued with a preliminary design of the column. A novel approach to design of the column's electromagnetic lenses combined both permanent magnets and magnetic coils, significantly reducing the required lens power and weight. Prototype condenser and objective lenses were built and tested to prove that this approach was viable. Once the electron-column design was set, the second phase ended with a selection of other major system components. Based upon the results of the second phase, a 0.1-micrometer (4-micro-inch) resolution SEM is feasible. The total system would weigh $52-\mathrm{Kg}$ including a 7-Kg electron column. A third phase would be to assemble and field-test a portable SEM based upon the results of the second-phase design. The third phase has not been funded.
\end{abstract}




\section{INTRODUCTION}

In principle, the intrinsic features of a TLI provide a basis for a unique identification that would be highly resistant to removal or transfer. Surface features contain inherent attributes for tagging provided the tagged portion is protected from damage or other degradation. Two such intrinsic attributes are surface roughness and composition. An electron microscope is particularly useful because it can determine micron/sub-micron surface topography (with three-dimensional characterization) in full depth-of-field while also measuring surface composition from characteristic X-rays. Optical microscopes cannot approach these capabilities. Because of the SEM's powerful capabilities, a tag based on authentication through direct intrinsic-surface measurement is also more difficult to counterfeit than any other practical tag. Under funding from the DOE Office of Arms Control, the direct SEM approach has been investigated to ascertain its strengths and drawbacks. This is a final closeout report on work conducted to date.

An alternative means exists that makes indirect use of an SEM: that is, to make plastic castings of the surface, bringing these castings to the SEM which could be fielded at the inspection site or installed at the inspection agency's headquarters. In this case, the castings record only the microscopic surface topography without detailed information on its atomic composition.

The direct SEM approach has the advantage that it provides possibly the most secure tag of any type, but it would probably only be needed for high-valued strategic weapons. The indirect plastic-casting approach, which is being investigated and reported separately, has the advantage of being a simple and low-cost secure tag.

\subsection{Proof-of-Concept Portable Scanning Electron Microscope}

\subsection{Introduction to Phase-One}

The objective of the first phase effort was to develop a proof-of-concept portable Scanning Electron Microscope (SEM) that can be mounted on the curved surface of a simulated Treaty-Limited Item (TLI) and record images at resolutions of 1 micron or better. Essential to this effort was development of a technique for mating an SEM to a typical TLI surface. Microscopic authentication of a TLI is accomplished by recording the TLI's surface topography during a field inspection to the micron level and matching these features with a reference image recorded during the TLI baseline inspection. Since this tag is based on the ability to image and record three-dimensional micron-level surface topography and atomic composition, the instrument most suitable for this task is the SEM. Some of this work was previously reported as part of Reference 1 . 


\subsection{Technical Results and Discussion}

\subsubsection{TLI Curvature and Surface Roughness}

Since the SEM electron column must be vacuum-sealed to the TLI surface, a highlycurved, rough surface provides the greatest challenge to attaining a suitable seal. The representative TLI surface imaged by the proof-of-principle portable SEM consisted of a 0.6 $\mathrm{cm}$ thick aluminum plate, bent into a semi-circle approximately 0.6 meters in diameter. This approximates the curvature of a cruise missile, so it is representative of a highly-curved TLI that might be tagged. Furthermore, the plate had relatively deep rolling marks, consisting of long grooves, that could provide leak paths under the seal. These grooves made the plate more difficult to seal than a polished surface typical of aircraft aluminum.

\subsubsection{Proof-of-Concept Portable Scanning Electron Microscope}

Although scanning electron microscopes are routinely used for surface studies of materials, commercially available instruments are not suitable for use in TLI verification because of two limitations. First, the instruments tend to be designed to attain nearnanometer-level resolution on specimens of limited size (typically a few centimeters in diameter and of similar thickness). These relatively small specimens are introduced into the microscope's small vacuum chamber. This chamber is integral to the microscope, which makes it impossible to examine a large object such as a TLI. The second limitation is that commercial instruments are not ordinarily portable, and the specimen of interest must be brought to the microscope. The concept of interfacing an SEM to a TLI to overcome these limitations is shown in Figure 1.1. Of paramount importance is the size of the SEM, its portability, and its ability to mount directly to the external TLI surface. For the first phase of this project, a used SEM was procured (at a cost of $\$ 6,000$ ), dismantled, modified, and restored to operational mode. Technical requirements necessitated changes to the electronoptics, detectors, specimen chamber, and vacuum system.

The instrument, designated the Portable SEM or PSEM, is shown attached to the TLI surface in Figures 1.2 and 1.3. The principal design modification involved rinoving the microscope's vacuum chamber and designing an interface chamber that is positioned between the electron column and the TLI. A vacuum seal to the TLI is an integral part mounted on the bottom of the interface chamber. The electron detector (scintillator-photomultiplier) used for both secondary electron imaging (SEI) and backscattered electron imaging (BEI) was the original detector supplied with the microscope. It was repositioned to be mounted in one of 


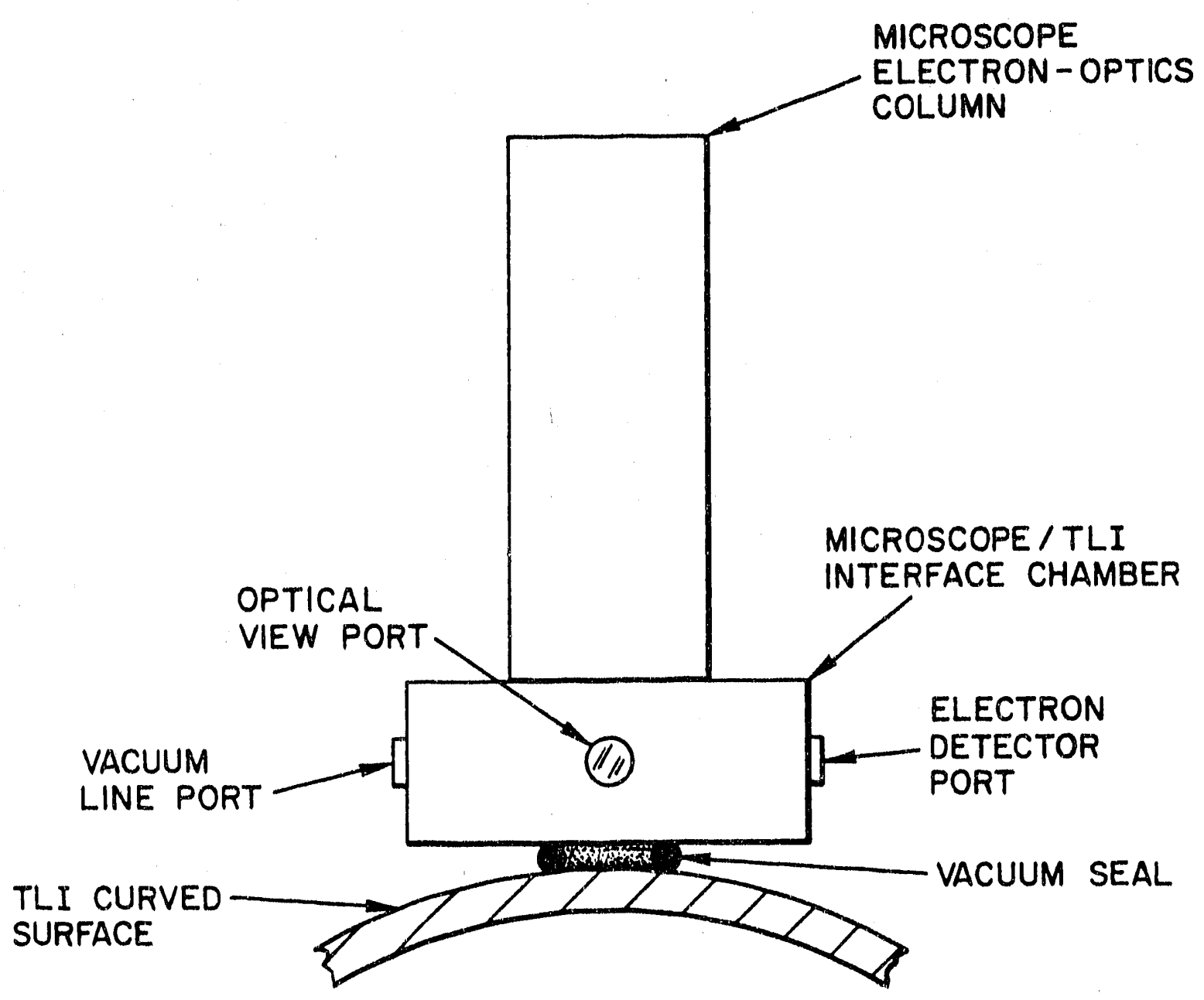

Figure 1.1 Schematic Illustrating Mating a Portable SEM to a Curved TLI 


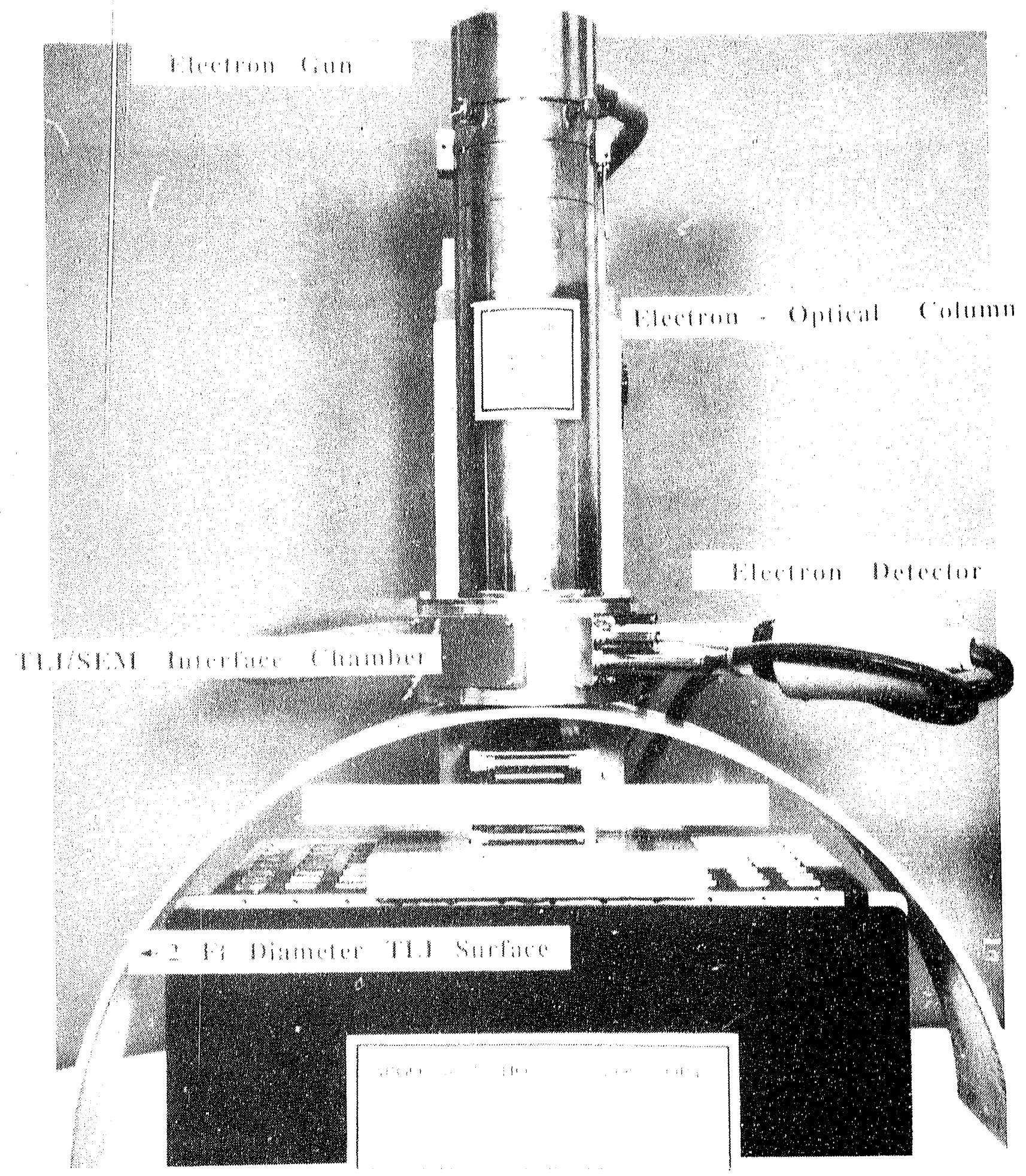

Figure 1.2 Scanning Electron Microscope-TLI Surface, Close-up Photo 


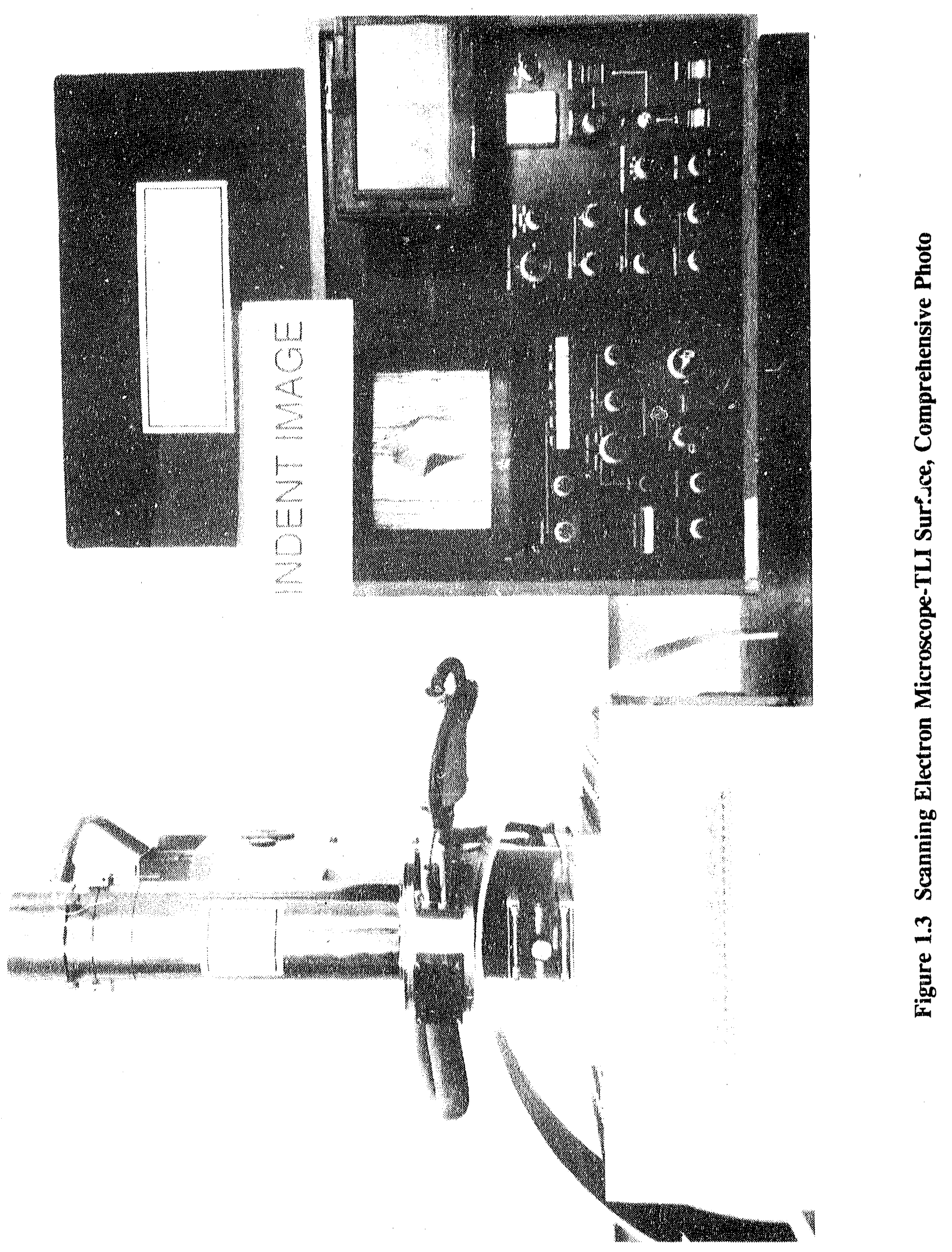


the side ports of the interface chamber. Another side port was used to pump out the chamber.

Figure 1.3 shows the PSEM in operation. Note that the TLI surface is being supported solely by the vacuum created by the PSEM. An image of part of a TLI authentication zone is shown on the viewing screen of the PSEM, by means of a double exposure. This image in Figure 1.3 is shown in greater detail in Figure 1.4. The depression in the center of this figure is that of an indent formed by hammering a small drill bit into the surface. Horizontal lines in Figure 1.4 are grooves made in the surface by the rolling mill used to form the plate. At this magnification, surface topography features of about 5 microns are resolved. Subsequent testing has resolved TLI surface features as small as 1 micron.

Achieving the proper vacuum in the SEM column and the TLI/SEM interface chamber is necessary to make this design viable. Lower vacuum levels in the chamber can be tolerated if the tungsten-filament electron-gun at the top of the column can he held at higher vacuum. Tolerance of a lower chamber vacuum level makes it easier to seal the chamber to the TLI. A higher vacuum level near the filament is necessary to prevent oxidation that shortens filament life. These different vacuum levels are achieved by pumping the chamber and the column through separate vacuum lines. In addition, achievement of different vacuum levels is aided by only allowing vacuum contact between the column and the interface chamber through a small differential aperture necessary for the electron beam to pass through. The method used to achieve these different vacuum levels is referred to here as differential pumping.

It was experimentally determined that backscattered electron and secondary electron imaging could be achieved at vacuums of $10^{-3}$ Torr in the TLI/SEM interface chamber. Interpretable backscattered electron images were obtained in vacuums as poor as $5 \times 10^{-1}$ Torr. No images could be attained at vacuum levels worse than $10^{-1}$ Torr, as excitation of secondary electrons within the vacuum environment saturated the detector system.

Once differential pumping was implemented, minimization of the leak between the interface chamber and the TLI proved to be relatively easy to accomplish. Simple vacuumgreased, flat, rubber O-rings provided a suitable seal. However, a greased, rubber, ring seal that conformed to the curvature of the TLI proved to be more reliable, and reduced the pump down time. 


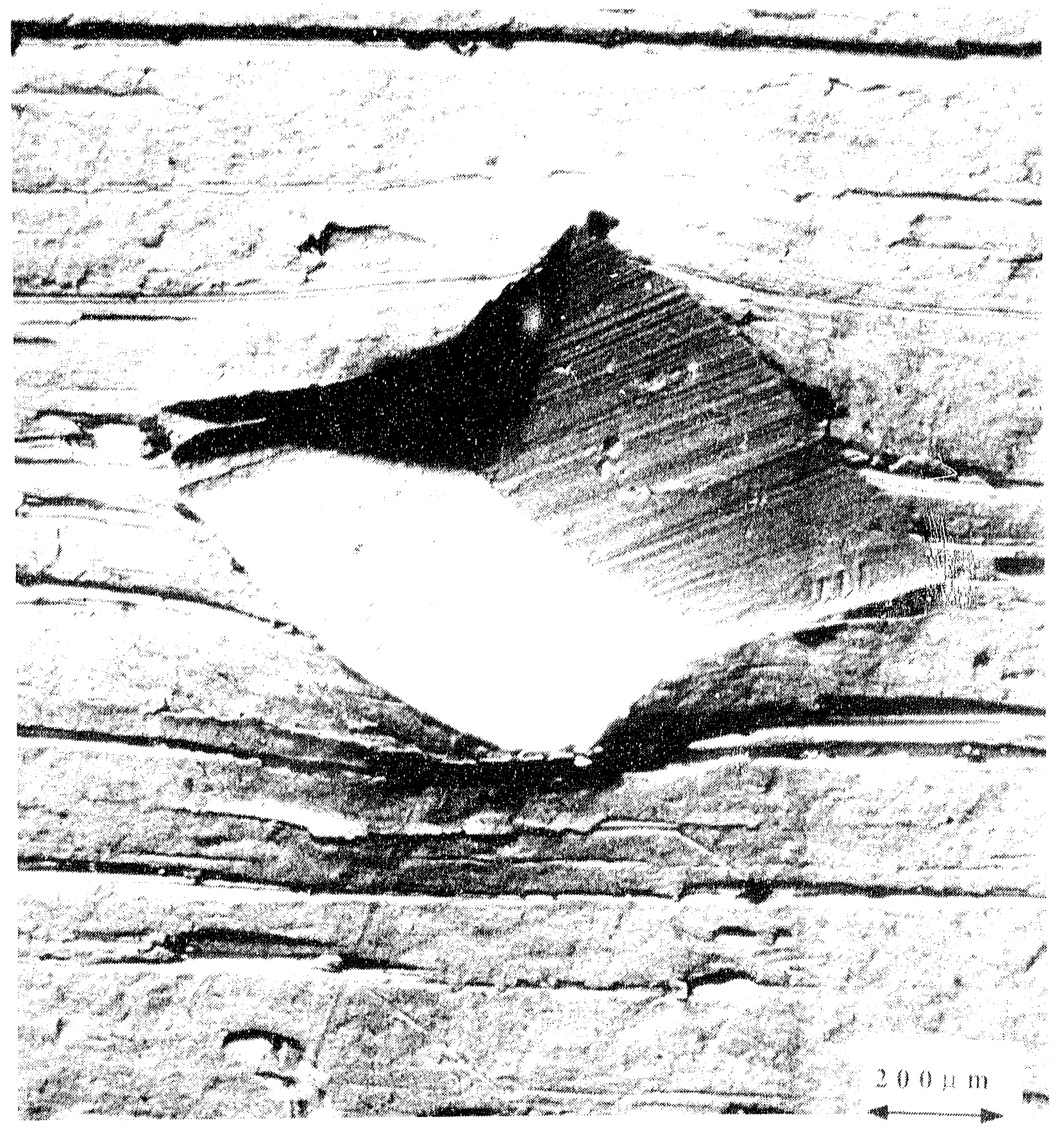

Figure 1.4 Scanning Electron Microscope Photo of TLI Surface with a Drill Bit Indent 
Vacuum levels in the electron-optical column were kept near $10^{-5}$ Torr at the electron gun, with a 300-micron-diameter differential aperture in the objective lens region. The differential aperture also served as the probe-defining aperture in the electron optics of the system. Aperture size limits the resolution of the SEM due to spherical aberration of the lenses.

\subsection{Conclusions from Phase-One Portable SEM Development Effort}

A proof-of-concept portable SEM was developed that interfaced to a cylindrical, metallic, simulated TLI surface. Both secondary and backscattered electron imaging of unique TLI surface features were accomplished. This PSEM has a nominal one-micron resolution, and can successfully image a rough, three-dimensional, TLI-tag surface.

\subsection{Design of a Portable SEM for Tagging TLIs}

\subsection{Introduction to Phase-Two}

Phase-two of this study was a design evaluation of a portable SEM optimized for arms control tag reading. Three considerations drove the evaluation. The first consideration was that alternative, portable SEMs had been built, and these designs had to be evaluated for suitability to tag reading. Another consideration was to use the experience and insights gained from Phase-one of this program. The third consideration w/as that it became apparent early in Phase-two that the electron-column design drives the selection and design of the rest of the system. It was then decided to concentrate effort on producing an electron column that would result in a low-power, light-weight, portable SEM optimized for tag reading.

\section{$2.2 \quad$ Other Portable SEM Designs}

\subsubsection{NASA's SEMPA Design}

NASA (Ref. 2) has had a continuing effort in developing a Scanning Electron Microscope and Particle Analyzer (SEMPA) to be used on spacecraft for analysis of comet dust particles. A working prototype of the SEMPA exists at the Jet Propulsion Laboratory in Pasadena, California. As part of this evaluation, a site visit by ANL personnel was made to the Jet Propulsion Laboratory to evaluate this design. There are three unique features of this instrument compared to a commercial SEM: 
1. The instrument has two lanthanum boride electron guns to provide redundancy in case of gun failure.

2. The microscope uses electrostatic lenses to lower the power requirements. All commercial SEMs use electromagnetic lenses.

3. The energy-dispersive, X-ray detector must either be partially or totally uncooled because of the unavailability of liquid nitrogen in space.

Even though this instrument is designed to work aboard a spacecraft, a small ion pump is necessary to operate the microscope during the final pre-flight testing period.

\subsubsection{Raith's Design}

The H. Raith KG Company, Dusseldorf, Germany has marketed a portable SEM. This system is called the Raith Pearl SEM. One of the authors (N.J. Zaluzec) visited Raith, and his trip report with a photu is included as Appendix A. In contrast with the NASA design, the Raith is basically a rugged, commercial SEM similar to the Phase-one SEM reported in Section 1. Some features of the Raith SEM are:

1. A single, tungsten-filament, electron gun typical of a cornmercial SEM design.

2. A typical commercial electromagnetic lens design.

3. A standard, liquid-nitrogen cooled, energy-dispersive, X-ray detector.

4. Vacuum is achieved by a turbo pump directly attached to the electron column. This feature reduces the amount of vacuum plumbing compared to commercial SEM designs.

\subsubsection{Discussion of Other Designs}

The Raith Pearl design came closest to being suitable for tagging. In fact, one could consider using the Pearl in field-tagging exercises. However, the column weight $(23 \mathrm{Kg})$ and power requirements (220 volts, 10 amps) could be greatly improved upon for an SEM dedicated to tagging. Furthermore, direct attachment of the turbo pump to the SEM column induces vibrations that limit the resolution of the Raith SEM. 
The NASA microscope was ideally miniaturized in both its power (28 watts) and total weight $(17 \mathrm{Kg})$. It is important to note the high-voltage, electrostatic lenses in the SEMPA must be exposed to the column vacuum. This exposure creates two serious problems for a tagging SEM. The first problem is that the lenses are exposed to a relatively poor vacuum, so the high voltage necessary to operate these lenses would attract contamination that degrades the lens performance. The second problem is the increased pumping volume relative to a design where the lenses are not in the vacuum. In addition, the lanthanum boride electron guns require a better vacuum than can be achieved by differential pumping.

\subsection{PSEM Lens Design}

\subsubsection{Optimizing a PSEM for Arms Control Applicatior.s}

In a typical commercial SEM, the electron beam travels from the gun through two condenser lenses and one objective lens before impinging on the sample. Commercial lenses must provide the flexibility to accommodate a wide range of beam-acceleration voltages as well as working distances. The working distance is the distance from the objective lens to the sample. In contrast, an SEM dedicated to reading tags can be designed to operate over a much narrower range of parameters. For instance, a tagging SEM can operate at a constant beam acceleration $(\sim 15 \mathrm{Kv})$ and a fixed working distance $(\sim 25 \mathrm{~mm})$. Narrowing the operating parameters can allow for a large saving in the power needed to excite the condenser and objective lenses. This is achieved by supplying each lens' magnetic field through a combination of a permanent magnet and an electromagnet. As much of the magnetic field as possible is provided by the permanent magnet, while the electromagnet is used to adjust the field above and below the constant level provided by the permanent magnet. Since the electromagnet is needed only to adjust the field, there is a large power and a considerable column-weight savings over a purely electromagnetic, commercial lens design.

\subsubsection{Measurements Made to Define Magnetic Field Requirements}

The prototype PSEM, described in Phase-one, was used to define the necessary magnetic field strengths for the new lens designs. Figure 2.1 shows the results of measurements made upon the/prototype PSEM for the narrowed range of beam voltage and working distance required of an SEM dedicated to tagging. The magnetic field was measured with a Hall probe for both condenser lenses and thc objective lens. All lenses followed linear relations between the field strength and lens current. The necessary magnetic field-strength range for each type of lens is defined by the cross-hatched area. For each type of lens, the range is defined by two points of contact of the cross-hatched area with the straight line. 


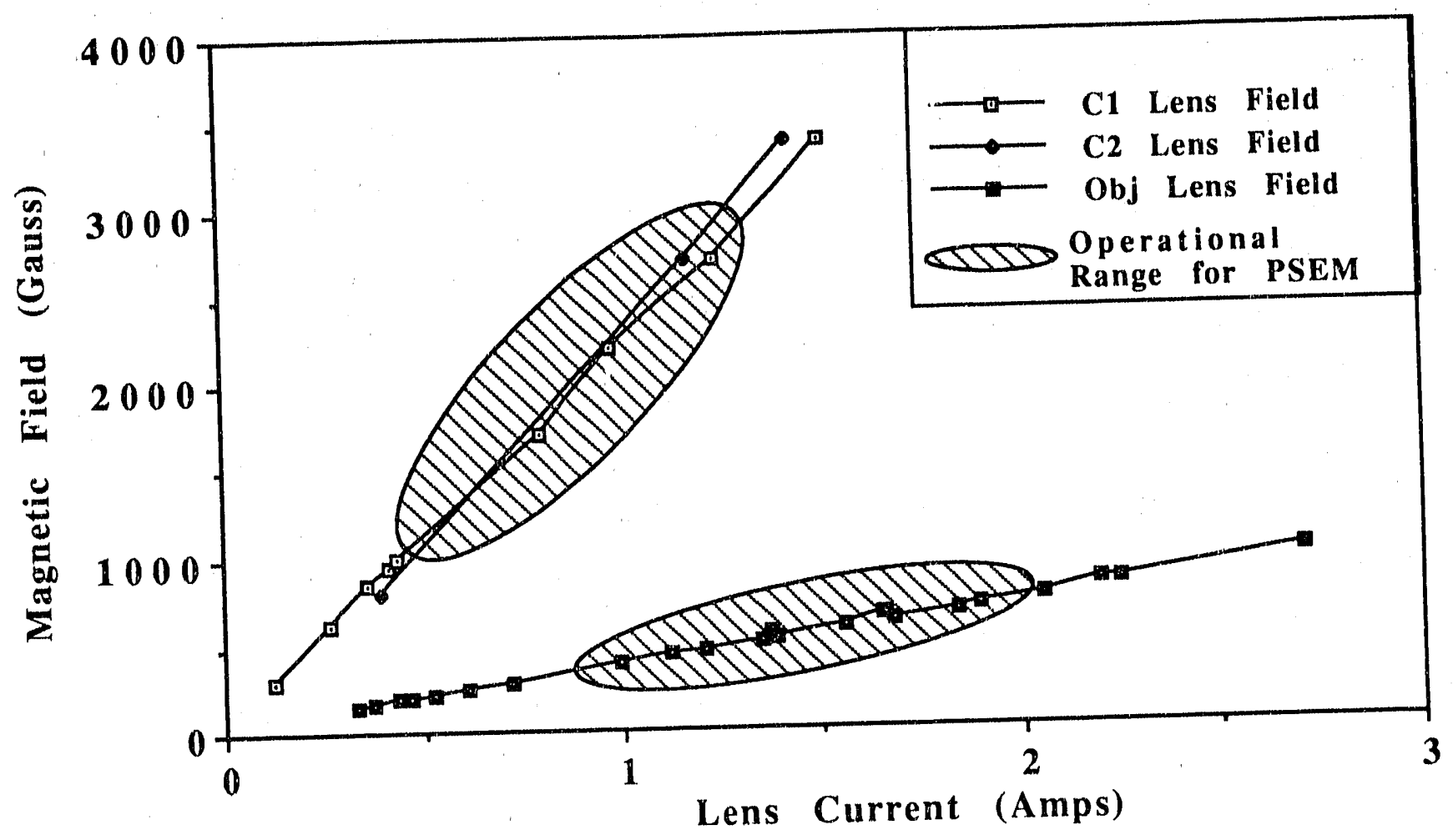

Figure 2.1 Measurements of Phase-one PSEM Operating Parameters 


\subsubsection{New Lens Design}

Specific designs for the condenser and objective lenses are shown in Figures 2.2 and 2.3 , respectively. Both designs position the excitation coils above the permanent magnet and enclose the magnet assembly in an iron/stainless-steel magnetic shroud. For the condenser lens, the magnetic coils are closer to the center of lens because they must provide more adjustment to this lens compared to the adjustment the coils must provide to the objective lens. In addition, the permanent magnet in the condenser lens is larger and closer to the bore of the lens. This is because the permanent magnet must provide a larger average field to the condenser lens than the permanent magnet must provide to the objective lens.

Figure 2.4 shows magnetic iield measurements made on the new lenses without permanent magnets installed. It is important to note the highly linear relation between field strength and lens excitation in this operational range. This linear relation is important to achieving an easily-controlled field strength in the composite coil and permanent magnet assembly. Note that both narrow and wide bore objective lens designs were pursued.

Figure 2.5 presents the extrapolated performance of the objective and condenser lens designs with the permanent magnets installed. For both lenses, this figure superposes a linear extrapolation of the data in Figure 2.4 with the constant fields provided by the permanent magnets. The resultant fields are the linearly-variable field strengths necessary for both condenser and objective lenses. Comparison of Figure 2.5 with Figure 2.1 shows the Phasetwo lens designs achieve the necessary field strength ranges. Therefore, the desired magnetic field strength can be supplied by a combination of a permanent magnet and a coil. The permanent magnet provides an average field, and the coils provide a field adjustment above and below the average field. Note that the wide-bore rather than the narrow-bore lens met the design requirement for the objective lens. 


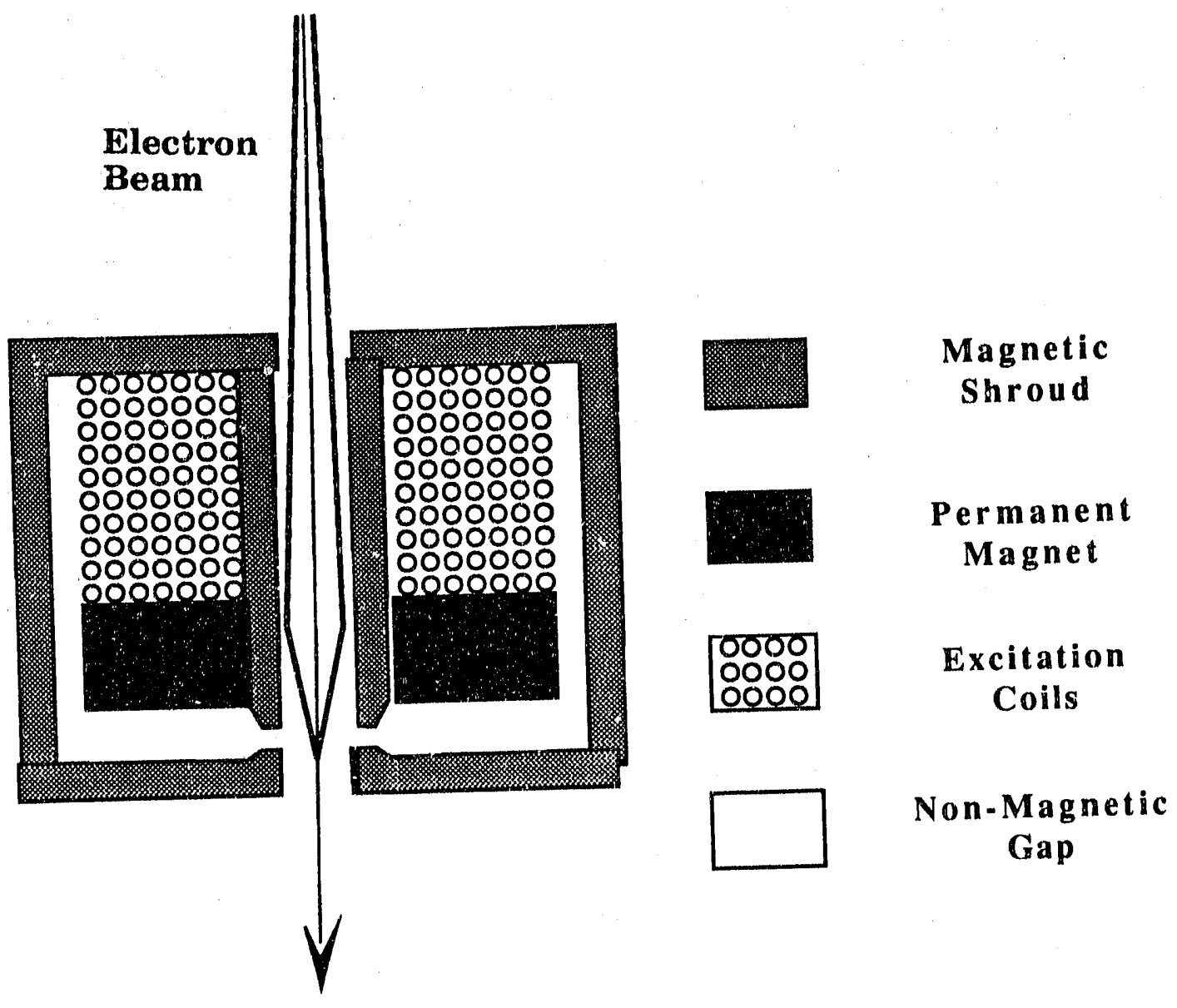

Figure 2.2 Condenser Lens Design 


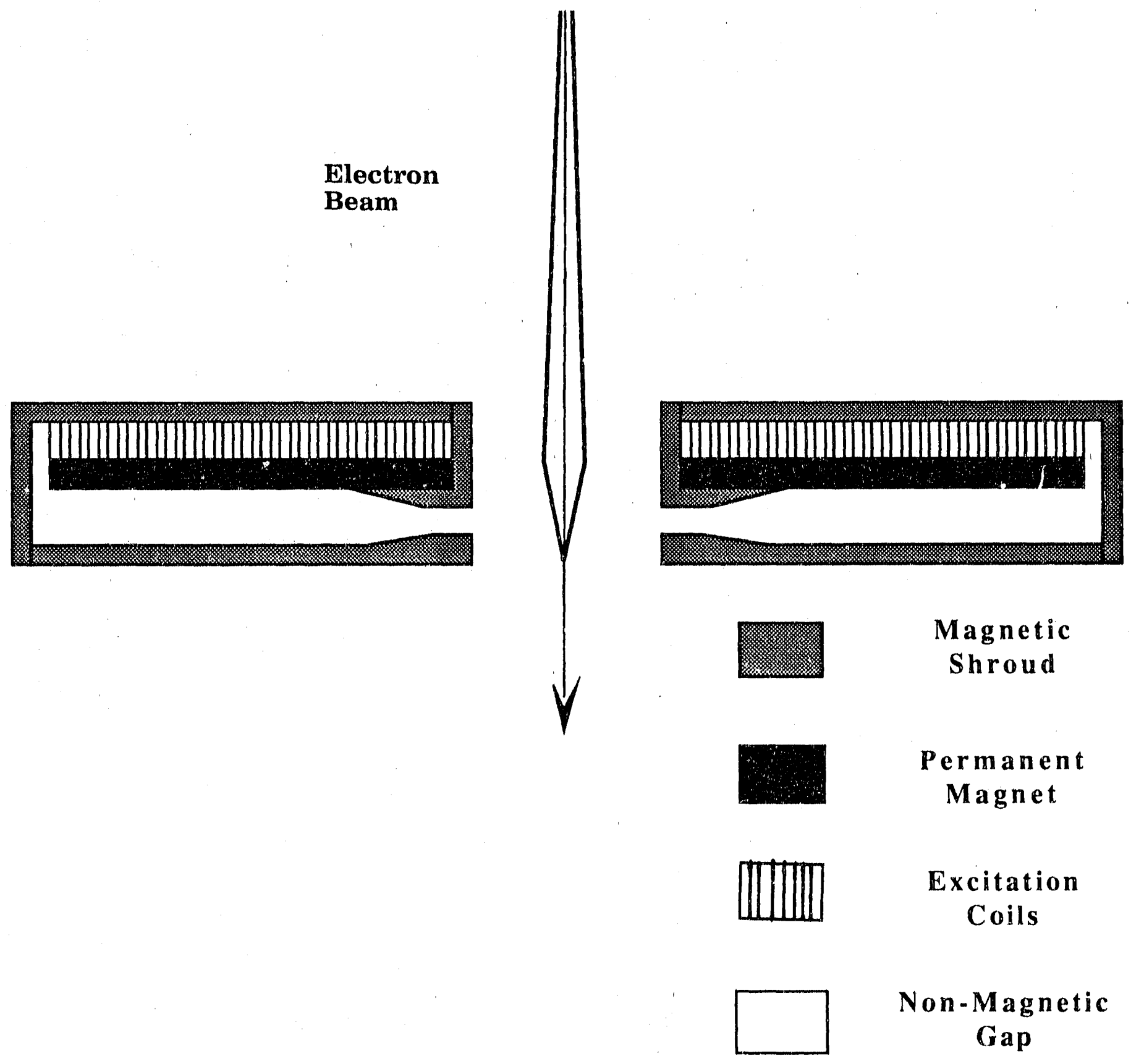

Figure 2.3 Objective Lens Design 


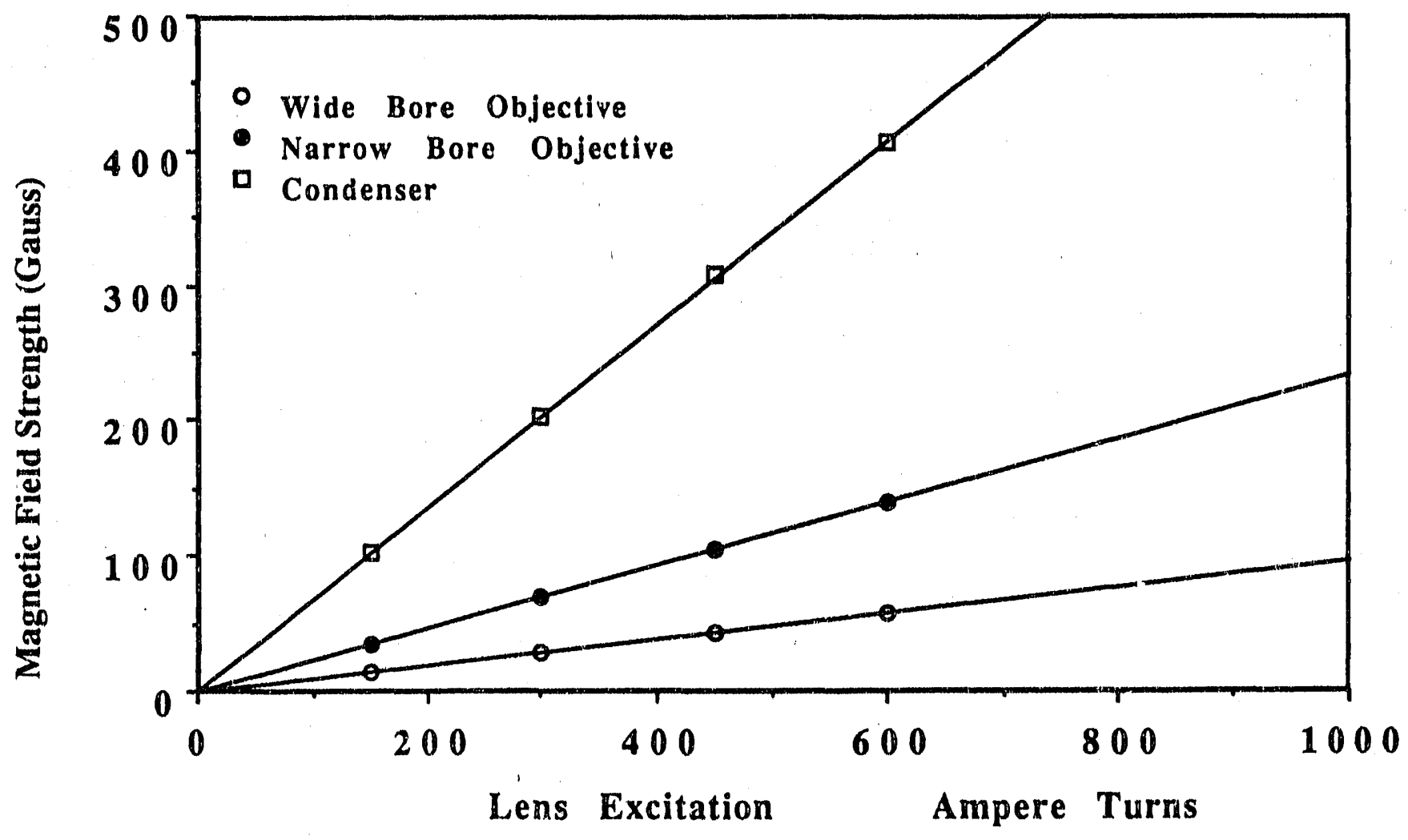

Figure 2.4 Coil Magnetic Field Linearity 


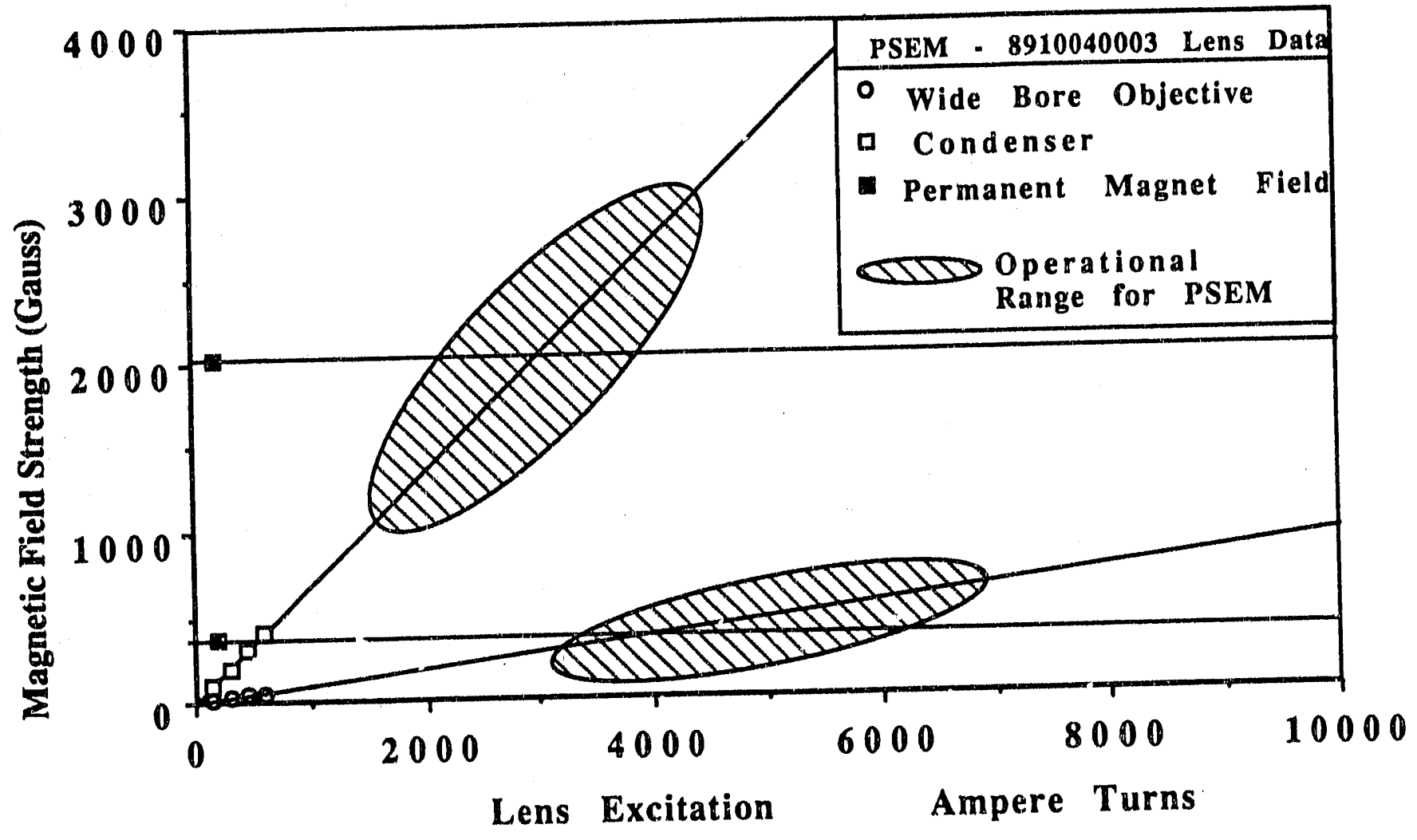

Figure 2.5 Performance of Lens Design 


\subsubsection{SEM Column Optimized for Tagging}

Figure 2.6 is a schematic of an SEM electron-beam column optimized for tag authentication. Figure 2.7 is a photo of a full-scale mockup of the column. As in a commercial SEM, there are two condenser lenses and one objective lens. The column has two sets of scan coils/deflectors between the lower condenser lens and the objective lens. These coils/deflectors cause the beam to raster scan the surface being examined. Stigmator coils are also shown mounted just above the objective lens to correct for astigmatism. Note that column components such as the tungsten electron gun and a differential aperture are not included in the nockup. It is estimated that a fully-operational version of this column would weigh less than $12 \mathrm{Kg}$. This should be compared with the $23 \mathrm{Kg}$ Raith column and the 17 Kg SEMPA microscope.

\subsection{Tagging SEM System}

Figure 2.8 shows a schematic of the entire tagging optimized SEM. The electron column and interface chamber are shown mounted on a cylindrical TLI. The column and the interface chamber are separated by a differential aperture (not shown) and are pumped through separate ports. This design feature, referred to as differential pumping, was incorporated in the Phase-one portable SEM. The vacuum pump is separated from the microscope by a vibration damping umbilical. Although the tripod in Figure 2.8 is shown supporting the column vertically, the column could be supported at any angle to the TLI and still be functional. A single cable from a control and display console supplies power to the microscopes's electron gun, electron optics and electron detectors. Both secondary and backscattered detectors would be used. The cable also returns the image signal from the electron detectors. A computer and text screen connect to the command and control console. The entire system is computer-controlled for reliability and ease of use. Field and baseline image comparisons are also done by this computer.

Many design selections were made for this SEM. Table 2.1 summarizes the major selections and their motivations. This table is broken down in sections on the electron source (electron gun), electron lens, beam scanning system, electron detectors, and the vacuum system. 
First

Condenser

Lens

Second

Condenser

Lens

Upper Scan
Coils/Deflectors

Lower Scan

Coils/Deflectors

Stigmators

Objective

l. ens

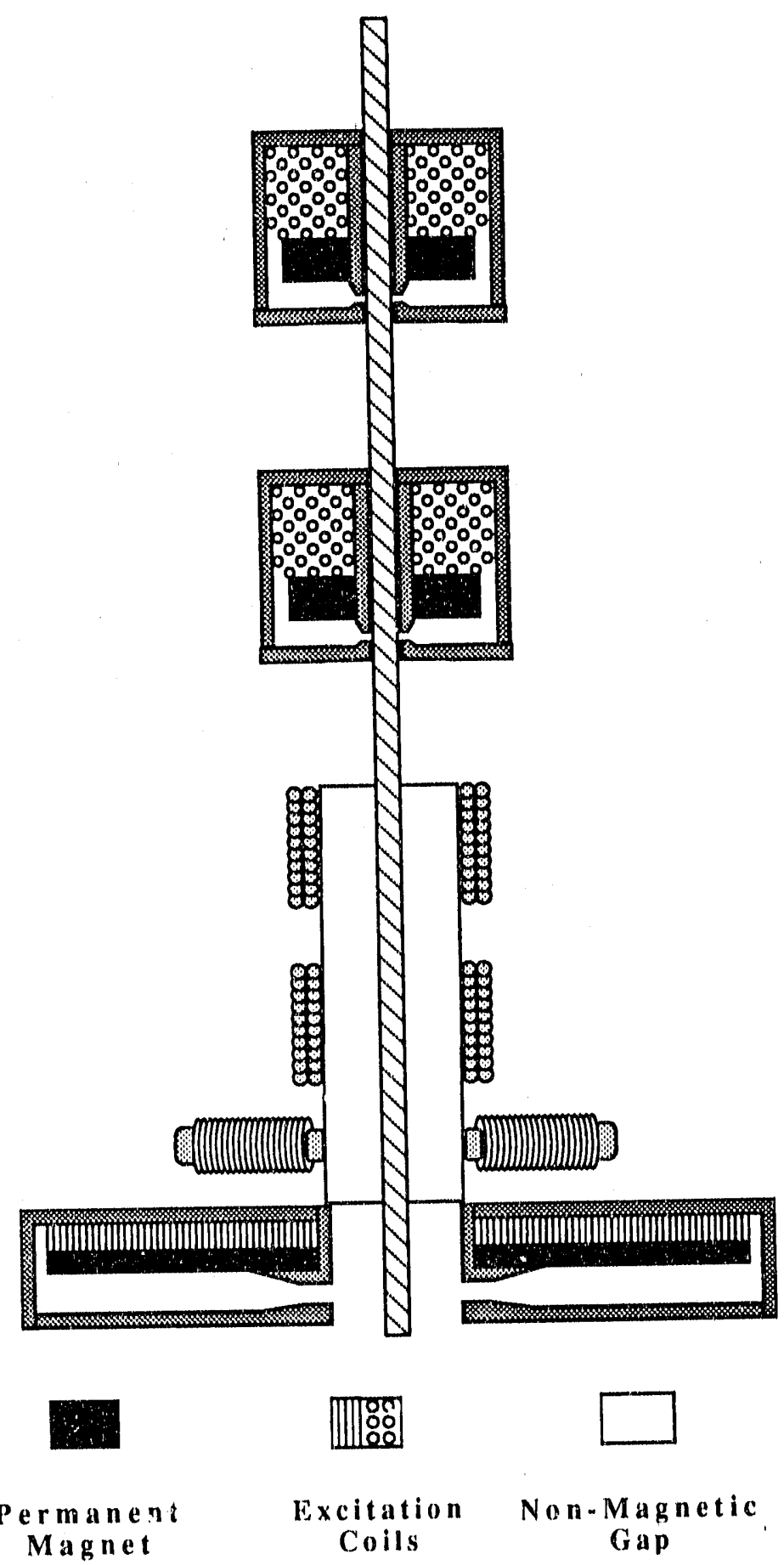

Magnetic

Shroud

Magnet

Coils

Gap

Figure 2.6 Schematic of a Tagging SEM Electron Column 


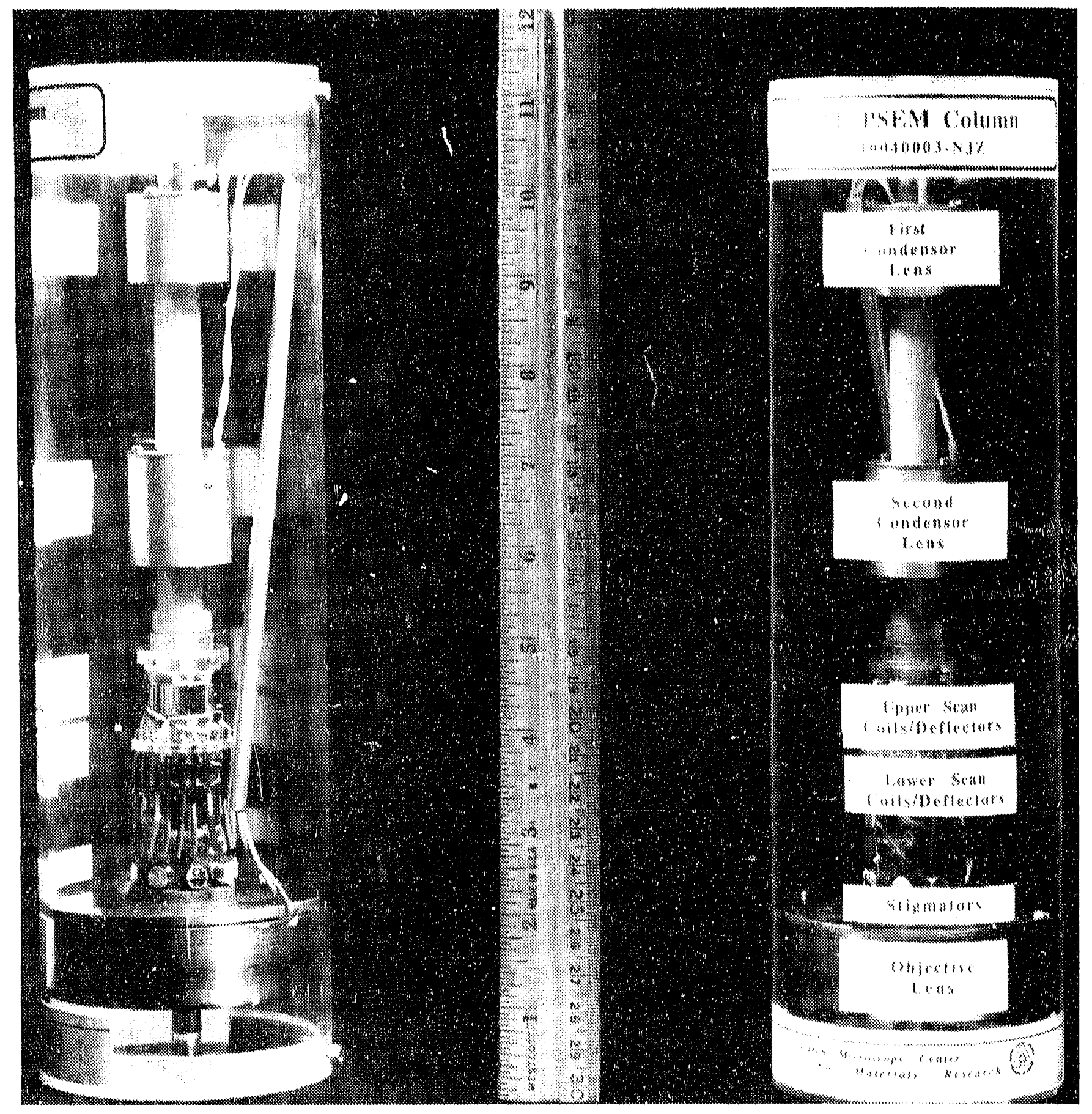

Figure 2.7 Photo of 'Tagging SEM Electron Column Mockup 


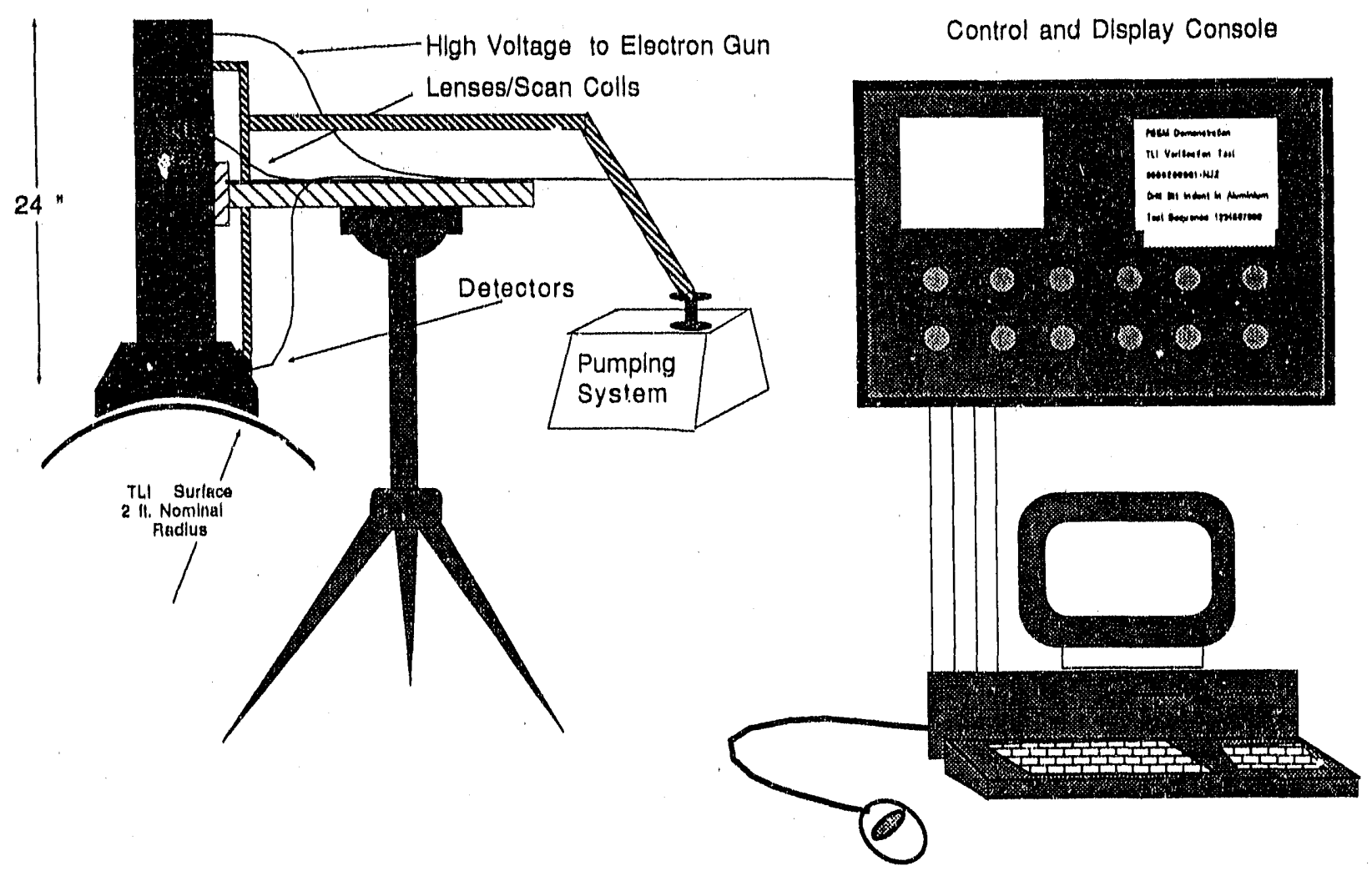

Figure 2.8 Schematic of Tagging Optimized SEM 
TABLE 2.1 SELECTION AND MOTIVATION FOR MAJOR COMPONENTS

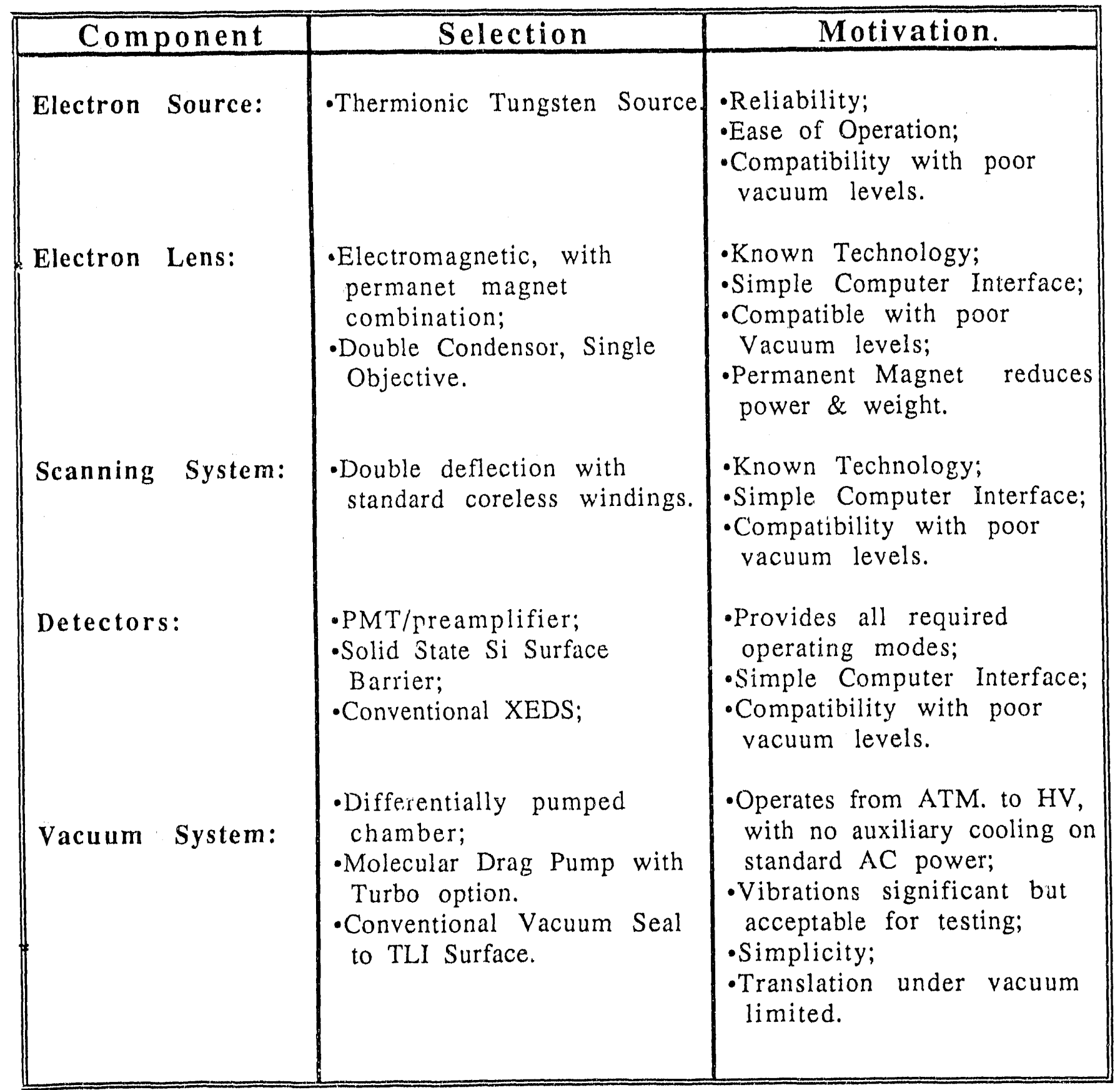


Table 2.2 summarizes and compares important component features from the Phase-one and Phase-two designs. This table is broken down into sections describing the electron column, electronics, umbilicals, vacuum pumps, power requirements, image resolution, and microanalysis techniques used for authentication. Note the Phase-two design provides for a lightweight, low-power, compact, portable SEM, suitable for field usage.

One additional step would be required to authenticate electrically-insulating TLI surfaces. These must be made conducting by sputter-coating a thin, gold coating onto the surface prior to the baseline examination. A portable sputter coater would be relatively simple to construct, and the necessary vacuum could be provided by the SEM's vacuum pump. Another option is to build the sputter coater into the PSEM.

\subsection{Safety Issues}

The most important safety concern is the presence of high voltage. In many potential applications, this would not be a concern except when volatiles are present. Missile silos are susceptible to explosions ignited by high voltage discharges. High voltages are needed to power the SEM electron gun, the sputter-coater and the cathode ray tubes (CRTs) associated with the SEM screen and the control computer's text screen. The umbilical cable must be carefully insulated and grounded in order avoid static charge. The electron beam impinging on the TLI is very feeble (a few pico-amps), so it does not heat the TLI appreciably. In addition, because the beam only impinges on the TLI when there is a good vacuum, it cannot ignite flammable vapors outside the electron column. The electron beam will no longer impinge on the TLI when vacuum is lost, and the high voltage can be engineered to be quenched if vacuum is lost. Other tag systems also use CRT tubes in close proximity to the TLI, so the SEM tag system has some safety concerns in common with other tag readers.

\subsection{Conclusions from Phase-two Design Efforts}

This work has established the technical feasibility of using a low power, lightweight, portable SEM to authenticate TLI tags. Future work would be to construct and fielddemonstrate the Phase-two design. 
TABLE 2.2 COMPARISON OF PHASE-ONE AND PHASE-TWO SEMs

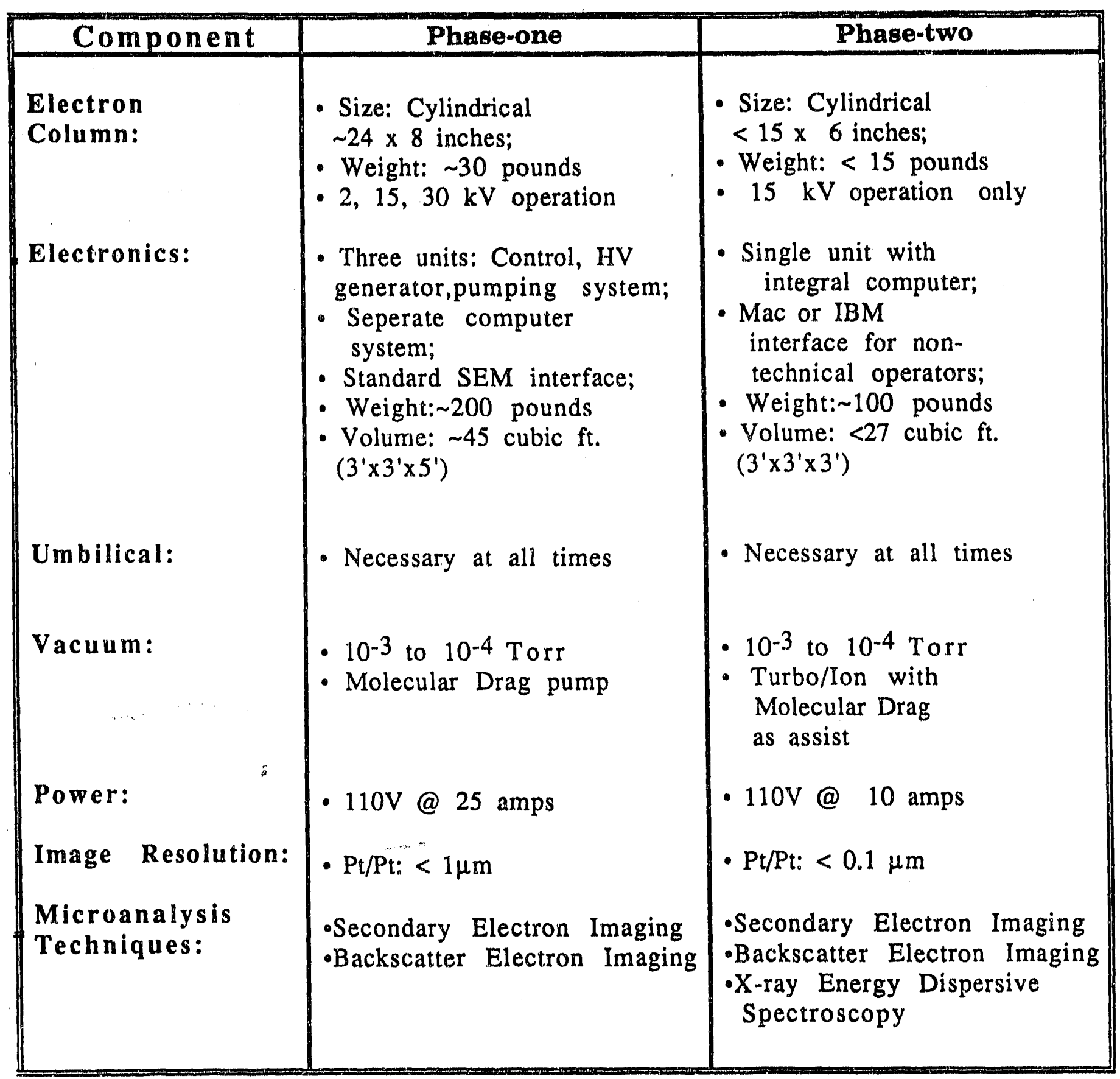




\section{REFERENCES}

1. Palm, R.G., et al., "Unique Tamper-revealing Tags for Arms Control Verification: Electron Microanalytical Authentication of TLI Intrinsic surface Labels", Argonne National Laboratory Report ANL/ACTV-89/1 (Jan. 1989).

2. Bradley, J.G., et al., "An Electromagnetic/Electrostatic Dual Cathode System for Election Beam Instruments," Microbeam Analysis--1986, 265-267. 


\section{ACKNOWLEDGMENT}

The Tagging project gratefully acknowledges the support extended to it by the U.S. Department of Energy, Office of Arms Control. The current program manager is Dr. James Fuller. Howard Heu was the original program manager. 


\section{Appendix 1 \\ Trip Report to Evaluate the Raith SEM \\ N.J. Zaluzec}

\section{Dusseldorf/Dortmund, West Germany}

On behalf of the Argonne National Laboratory (ANL) tagging program, a one day site visit was made to the $\mathrm{H}$. Raith KG company to evaluate the technical merits of their PEARL portable scanning electron microscope (SEM). In attendance from Raith were: H. Raith (company founder and president) and K. Kasperzik (electronics design). Raith is a small consulting and development company specializing in the development of accessory components for use in scanning electron microscopes (SEM's). It is located in the Technology Center of Dortmund University.

The motivation for the application of the SEM to treaty verification lies in the SEM's ability for high resolution imaging and microanalysis to uniquely fingerprint and subsequently verify treaty limited items. ANL has developed a prototype PSEM (portable scanning electron microscope) to investigate the tagging feasibility. Recently and independent of the ANL's work on the PSEM, Raith announced a portable SEM to the conmercial market. This visit was made to evaluate the suitability of the Raith PEARL System for tagging. Comprehensive notes and documentation of this site visit are in N.J. Zaluzec's possession, and only the highlights shall be summarized in this report.

Raith did not actually build and design this instrument. The instrument was constructed under subcontract by the Tesla Instrument Co. of Czechoslovakia to Raith's specifications. Tesla is a major Eastern-block manufacturer of electron optical equipment. However, very little of their equipment is purchased in Western countries. This may be an advantage for tagging applications as it means that Western technology is not being exported to the Eastern-bloc for treaty verification. However, most major commercial scanning electron microscope companies (VG, Philips, JEOL, Hitachi, Akashi, etc.) all export to the Eastern-block, and this may render the issue of technology transfer insignificant. 
The PEARL system is, for the most part, a conventional SEM having a double-gap condenser and single objective lens, designed to run primarily at TV rates at a fixed accelerating voltage of $15 \mathrm{kV}$ with a standard tungsten electron gun. The system is mounted on a mobile conical shaped chamber which is designed to mount directly onto the surface of the object of interest. The vacuum seal is made by means of a large well lubricated O-ring approximately eight inches in diameter. Vacuum is achieved by a turbo-molecular pump mounted directly on the chamber. Translation is accomplished by sliding $O$-rings laterally, and gives a motion of \pm 10 $\mathrm{mm}$. Smaller electronic translation of $\pm 4 \mathrm{~mm}$ (at magnifications $<1000 \mathrm{X}$ ) and $\pm 0.4 \mathrm{~mm}$ (at magnifications $>1000 \mathrm{X}$ ) can be accomplished electronicaliy by deflecting the incident electron beam. The column is approximately $45 \mathrm{~cm}(\sim 18$ inches) high and weighs approximately 23 kilograms ( $50.6 \mathrm{lbs})$. The power supplies and electronics console are mounted on a rolling cart of nominal dimensions $150 \times 60 \times 90 \mathrm{~cm}(\sim 5 \times 2 \times 3 \mathrm{ft})$, weighing roughly 80 kilograms $(\sim 200 \mathrm{lbs})$. Power required was $220 \mathrm{~V}, 10 \mathrm{~A}$. A photo of the electron column mounted on the hood of a van is shown in Figure A-1.

During this visit the entire electron optical column and most of the electronics were dismantled and reassembled to check their reliability and serviceability. The mechanical construction of the SEM column and electronics was judged sufficiently robust to endure even rough handling by inexperienced scientific equipment movers. Interlocks on the electronics shut down the high voltage on vacuum excursions, so the possibility of ignition of flammables by the electron beam is unlikely. High-voltage components appear to be suitably protected and well designed. Care equivalent to that used to move objects similar to a commercial television set would be sufficient to relocate this instrument without damage.

At present no plans are in place to address the issue of servicing of the instrument, as only two have been sold (both to a Dr. Balaschke of Bremen University, West Germany). Most good EM technicians could easily service the instrument should breakdown occur. Documentation was reasonably thorough and was in the process of being translated into English.

Nominal resolution of the system is limited by objective lens aberration, and vibration from the turbo-pump. Experimental measurements gave resolutions in the 0.5 micron range, with the clear limitation being the vibrations introduced by the turbo-pump system at any magnification greater than $5000 \mathrm{X}$. It was not possible to shut down the turbo-pump to test the intrinsic resolution of the objective lens electron optics. At present only secondary electron imaging is implemented, however, quadrant backscatter detectors can be fitted without much difficulty. 


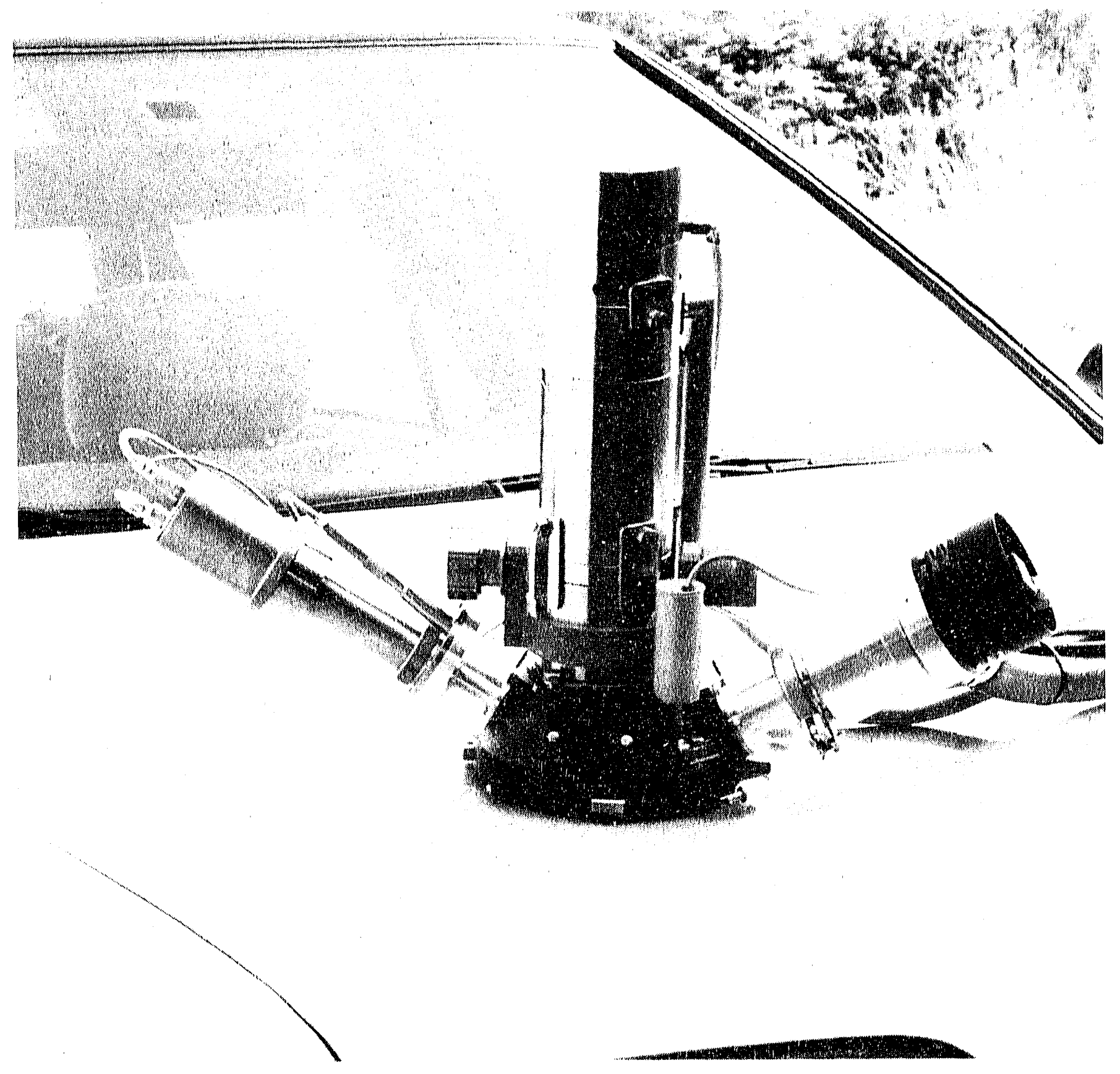

Figure A-1 Raith Pearl Portable SEM Examining Hood of a Van 
The system could be easily interfaced to external computer control for image acquisition via a PC based computer system as proposed in the ANL's portable SEM. Provision exists for external ramp input to the control electronics. This is similar to that generated by the SEMPER image processing system and would be clearly compatible with the I/O of that system.

In conclusion, the PEARL system could be adapted for use by the ANL tagging program for on-site verification and proof-of-principle demonstrations. It is an extremely simple system to operate and well interlocked for safety. Inexperienced users could be readily taught the routine operation of the system for low magnification studies (less than $\sim 1000-2000 \mathrm{X})$. It would not likely be an ideal candidate for high resolution studies, as the resolution $(\sim 0.5$ microns) is limited by mechanical vibrations introduced by the pumping system. The system is robust and could easily stand rough treatment in the field. 


\section{DISTRIBUTION FOR ANL/ACTV-91/3}

Internal

ANL Contract Copy

ANL Libraries (2)

ANL Technical Publications Services (3)

ANL Patent Department

A. Travelli (78)

R. Palm (45)

\section{External}

U.S. Department of Energy Office of Scientific and Technical Information (12) Manager, U.S. Department of Energy Chicago Operations Offlce 

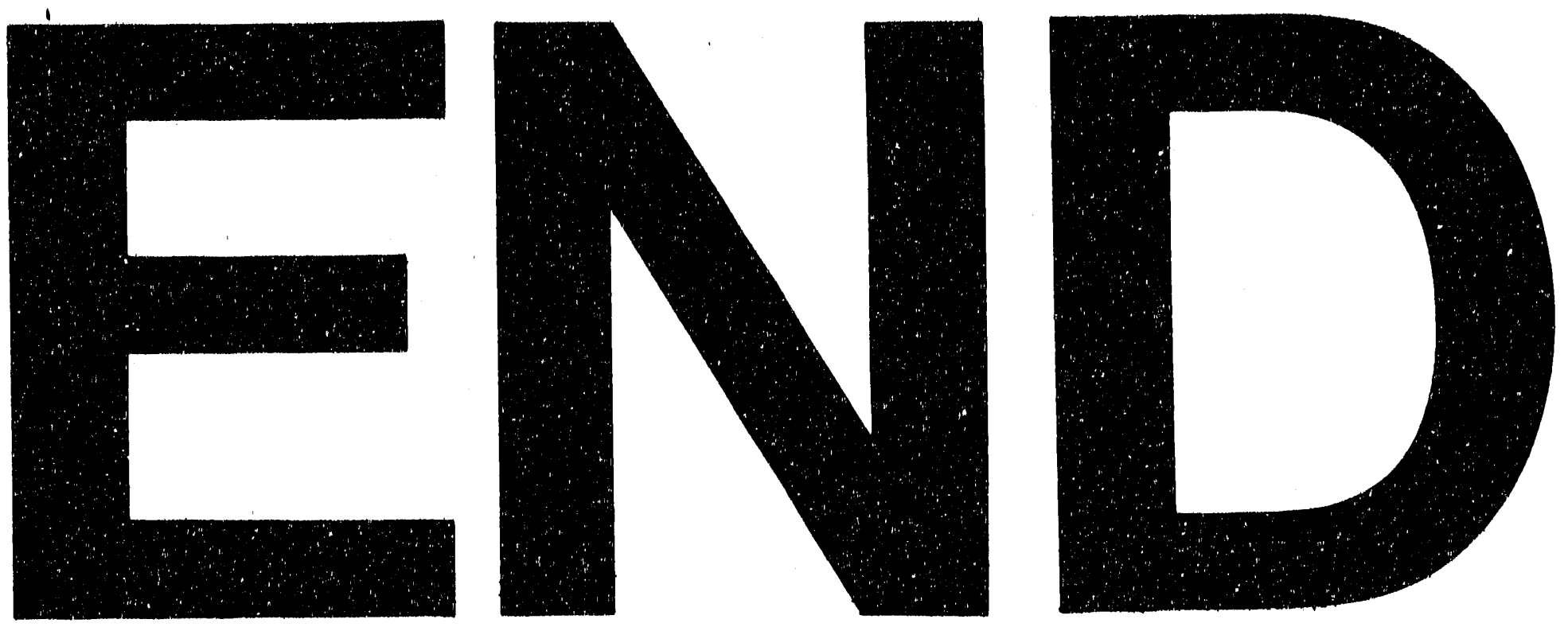

数

,
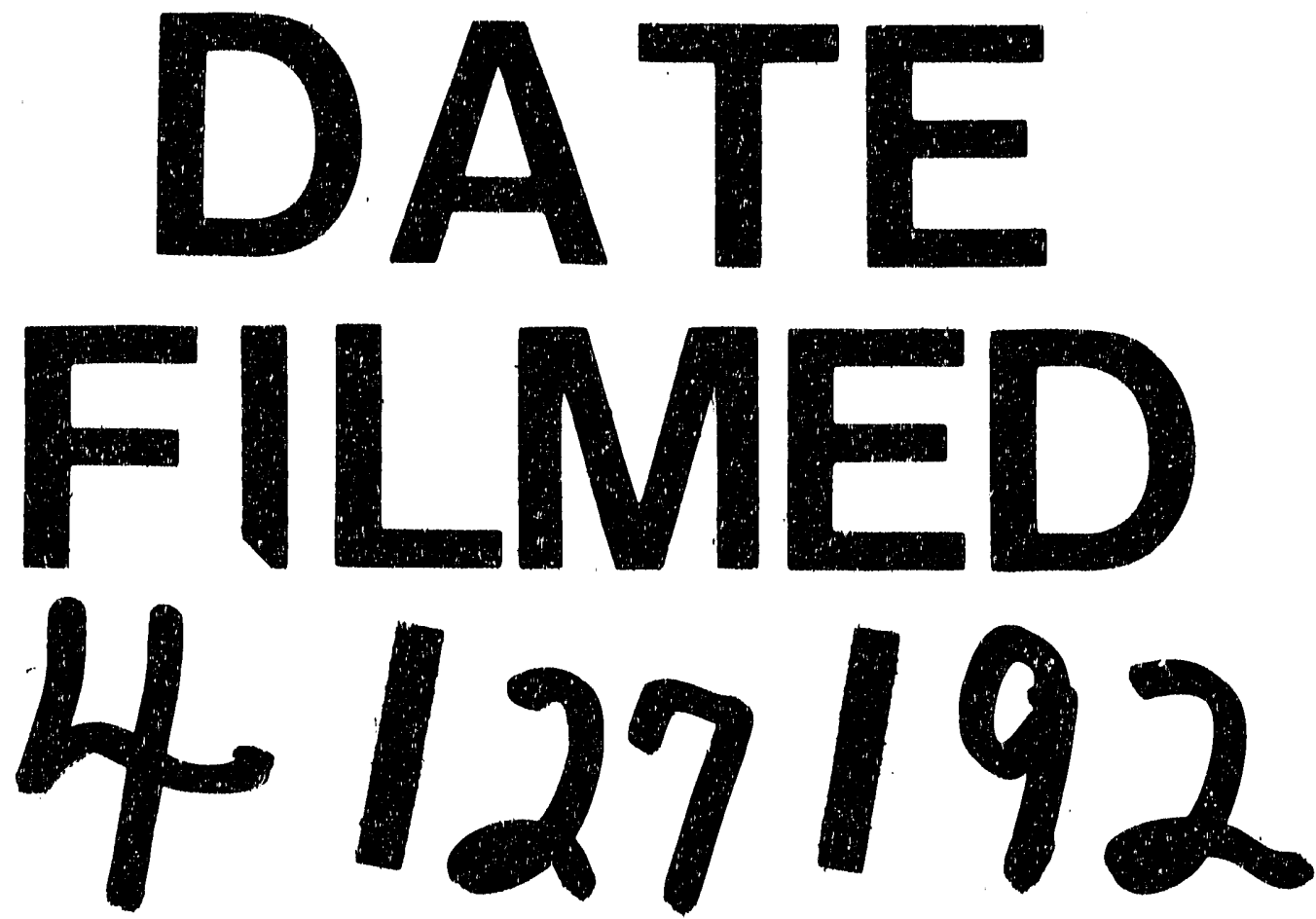
' 